\title{
Neonatal cholestasis: A red alert for the jaundiced newborn
}

\author{
Dinesh Pashankar MD MRCPUK, Richard A Schreiber MD FRCPC
}

\begin{abstract}
D Pashankar, RA Schreiber. Neonatal cholestasis: A red alert for the jaundiced newborn. Can J Gastroenterol 2000;14(Suppl D):67D-72D. Neonatal jaundice may indicate cholestasis rather than a benign, physiological condition. Any four-week-old newborn with persistent jaundice should have a fractionated bilirubin screen to determine whether the hyperbilirubinemia is unconjugated. Conjugated hyperbilirubinemia, a hallmark of neonatal cholestasis, is pathological and requires further investigation. These infants need prompt diagnosis, early intervention and careful follow-up to ensure continued growth and development. Recent progress in the physiology of bile flow is reviewed, and the evaluation and management of neonatal cholestasis are summarized. Further advances in delineating the cellular and molecular processes that regulate bile acid metabolism in both health and disease will lead to a greater understanding of the conditions causing neonatal cholestasis. Unravelling the etiopathogenesis of these neonatal cholestatic disorders will allow the development of novel diagnostic and therapeutic interventions that ultimately will effectuate the prognosis for these young patients.
\end{abstract}

Key Words: Bile flow; Cholestasis; Neonate

\section{Cholestase néonatale : signal d'alerte chez le nouveau-né atteint d'ictère}

RÉSUMÉ : L'ictère néonatal pourrait être l'indice d'une cholestase plutôt que d'un état physiologique bénin. Tout nouveau-né de quatre semaines atteint d'ictère persistant devrait subir une épreuve de fractionnement de la bilirubine afin de déterminer s'il s'agit d'une hyperbilirubinémie conjuguée ou non. L'hyperbilirubinémie conjuguée, signe d'appel de la cholestase néonatale, est pathologique et nécessite une évaluation plus poussée. Il importe de poser un diagnostic rapide, d'intervenir immédiatement et d'assurer un suivi rigoureux afin de favoriser la croissance de ces enfants. Le présent article fait état des progrès récents réalisés dans la compréhension de la physiologie de l'écoulement biliaire et présente un résumé de l'évaluation et du traitement de la cholestase néonatale. Les futures recherches sur les processus moléculaire et cellulaire qui régulent le métabolisme des acides biliaires chez les sujets en santé et malades permettront de mieux comprendre les causes de la cholestase néonatale. Le fait d'élucider l'étiopathogenèse des troubles cholestatiques chez les nourrissons facilitera la mise au point de nouvelles interventions diagnostiques et thérapeutiques qui, en fin de compte, détermineront le pronostic chez ces jeunes patients.
$\mathrm{C}$ holestasis, defined as a reduction in bile flow, leads to an abnormal accumulation in the liver, blood and extrahepatic tissues of biliary-derived substances such as conjugated bilirubin and bile acids (1). In healthy newborns, the cellular processes regulating the synthesis, transport and excretion of bile and, in turn, bile flow, are immature and do not function at normal adult levels. Healthy neonates, therefore, are relatively cholestatic compared with adults. This is termed 'physiological cholestasis of the newborn' (hypercholemia), and it may take several months for these processes to mature (2). In contrast, the more familiar term 'physiological jaundice of the newborn' is defined as the presence of an unconjugated hyperbilirubinemia in the first few weeks of life as a result of immaturity in the glucuronyl transferase conjugating enzyme systems. Although physiological cholestasis and physiological jaundice manifest in healthy newborns, there is no state of physiological conjugated hyperbilirubinemia.

Neonatal cholestasis is best defined as a clinicopathological syndrome resulting from a variety of conditions that disrupt normal hepatobiliary function during the newborn period. From a practical, clinical perspective, newborns with cholestasis are most often jaundiced. It is important to appreciate, therefore, that not all neonatal jaundice is physiological. Rather, the presence of jaundice secondary to conjugated hyperbilirubinemia (a hallmark of neonatal

Division of Gastroenterology, British Columbia's Children's Hospital, University of British Columbia, Vancouver, British Columbia Correspondence and reprints: Dr RA Schreiber, Room 1K2, Division of Gastroenterology, British Columbia's Children's Hospital, 4480 Oak Street,

Vancouver, British Columbia V6H 3V4. Telephone 604-875-2332, fax 604-875-3244, e-mail rschreiber@wpog.childhosp.bc.ca Received for publication January 15, 1999. Accepted February 5, 1999 


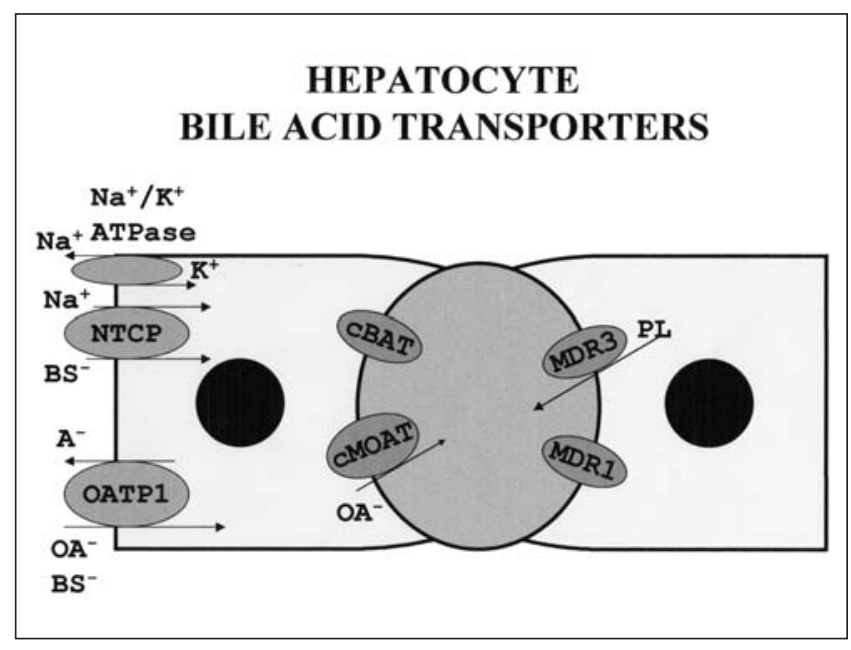

Figure 1) Hepatocyte bile acid transporters at the basolateral sinusoidal $\left(\mathrm{BS}^{-}\right)$domain; there are two principle transporters - the sodiumdependent taurocholate transporter (NTCP) linked to the sodium/potassium $\left(\mathrm{Na}^{+} / \mathrm{K}^{+}\right)$-ATPase pump and a sodium-independent organic anion $\left(\mathrm{OA}^{-}\right)$transporter $(\mathrm{OATP})$. At the canalicular domain, there are several ATP-dependent transporters (ATP-binding cassette proteins) belonging to the multidrug resistance (MDR) gene family. Multiresistance protein (MRP)-2 is a canalicular multispecific $\mathrm{OA}^{-}$transporter (cMOAT). MDR3 is a phospholipid (PL) transporter. $\mathrm{A}^{-}$Anion; cBAT Canalicular bile salt transporter

cholestasis) is pathological and a red alert for the jaundiced newborn. When an icteric newborn with cholestasis is encountered, it is essential that a diagnostic evaluation be conducted promptly to recognize disorders amenable to specific medical or surgical interventions, to initiate measures to improve bile flow and to prevent malnutrition by instituting appropriate nutritional regimens. In the present review, some of the novel developments in our understanding of the physiology and pathophysiology of bile flow as it pertains to the newborn are discussed. An update for the evaluation and diagnostic approach to the newborn with cholestasis and an outline for the management of neonatal cholestasis are provided.

\section{PHYSIOLOGY OF BILE FLOW}

In mature adults, bile acids are synthesized de novo in hepatocytes through the metabolism of cholesterol to cholic acid and chenodeoxycholic acid. These primary bile acids are then conjugated to taurine and glycine, and transported into the bile (2). In the intestinal lumen, bile acids act as detergents to promote intraluminal emulsification of dietary fat and help to facilitate the absorption of long chain fats and fat-soluble vitamins. A preponderant fraction of bile acids are absorbed in the distal third of the ileum by an active sodium-coupled transport mechanism (3). The remaining bile acids escape to the colon where they are first deconjugated and dehydroxylated by colonic bacteria to form the secondary bile acids, deoxycholic and lithocholic acids. Secondary bile acids reabsorbed from the small and large intestine return to the liver where they are resecreted (2). In mature adults, this enterohepatic circulation of bile acids represents the major portion of the total daily bile salt pool
( 2 to $4 \mathrm{~g}$ ), and only $10 \%$ of the bile salt pool $(500 \mathrm{mg}$ ) is derived from de novo hepatic synthesis.

A first step in the enterohepatic circulation of bile acids is hepatocyte transport of bile salts from the portal blood into bile (4). This vectorial transport of bile salts is a primary determinant of bile flow and is driven by several specialized active transporters at both the hepatocyte sinusoidal and canalicular domains. The predominant pathway for hepatocellular uptake of bile acids from the portal sinusoidal circulation is a $51 \mathrm{kDa}$ sodium-dependent taurocholate cotransporter protein (NTCP) located on the sinusoidal domain (Figure 1). This inward movement of a bile salt anion is coupled to the movement of sodium by an electrochemical gradient generated by the sodium/potassium $\left(\mathrm{Na}^{+} / \mathrm{K}^{+}\right)$ATPase pump. Sodium-independent bile salt uptake may also occur, as shown by the recently cloned organic anion transporting polypeptide. This polyspecific transporter mediates the transport of a broad range of substrates such as unconjugated and conjugated bile salts, bromosulfphthalein, other nonbile salt organic anions, steroid conjugates and cardiac glycosides. In adults, the hepatocellular uptake of bile acids from portal blood is extremely efficient, with a first pass clearance of $75 \%$ to $90 \%$.

In the past few years there have been a number of exciting developments in the molecular characterization of canalicular transporter proteins in both health and disease. The recently defined canalicular multispecific organic anion transporter, encoded by the multidrug resistance protein (MRP2) gene, is responsible for ATP-dependent elimination of amphipathic organic anion conjugates such as conjugated bilirubin or lithocholic acid. It is recognized that a genetic defect in the production of this transporter protein through a mutation in the MRP2 gene accounts for the Dubin-Johnson syndrome of conjugated hyperbilirubinemia (5). The ATP-dependent canalicular bile salt carrier is a canalicular transporter yet to be cloned but thought to represent the molecular basis for bile salt-dependent bile flow. An ATP-dependent flippase belonging to the family of ATP-binding cassette proteins is encoded by the multidrug resistance (MDR) 3 gene and responsible for phospholipid secretion at the canalicular domain. Recently, a defect in the expression of the MDR3 gene product was described in a subset of patients with progressive familial intrahepatic cholestasis (6). The creation of bile flow, therefore, is an active process dependent upon the action of a multitude of specialized hepatocyte transporter proteins at both the sinusoidal and canalicular domains. Dysfunction of any of these transporter proteins can lead to conjugated hyperbilirubinemia or cholestasis.

\section{PHYSIOLOGICAL CHOLESTASIS IN THE NEWBORN}

In early neonatal life, adult mechanisms for bile acid synthesis, uptake and excretion are immature. First, unlike in adults, where the principle circulating bile acid is cholic acid, the predominant primary bile acid at birth is chenodeoxycholic acid (7). Moreover, many other 'atypical' bile ac- 
ids circulate in the newborn, some of which are potently cholestatic (lithocholic acid). These findings suggest that the neonatal synthesis of bile acids is principally via an alternate pathway of cholesterol metabolism involving an initial 26-hydroxylation rather than 7-alpha-hydroxylation (Figure 2).

At birth, there is a relative paucity of the major NTCP on the hepatocyte basolateral domain (8). This transporter only increases in quantity in postnatal life to reach normal adult levels. Similarly, canalicular bile acid transporter systems may also be immature at birth, thereby limiting the transport of bile acids into the biliary sytem at the canalicular domain. The intestinal capacity for bile acid resorption at the ileum is limited in early neonatal life (9). In addition, because the neonatal colon is sterile, secondary bile acids are not produced. As a result of these developmental factors, the total bile acid pool in the newborn is decreased to about $30 \%$ that of normal adult levels (7). Thus, in neonates, the processes for bile acid metabolism are functionally underdeveloped, predisposing the infant to physiological cholestasis. It is not surprising that any insult to the hepatobiliary system in the newborn can manifest as neonatal cholestasis (1).

\section{CLINICAL PRESENTATION OF NEONATAL CHOLESTASIS}

Jaundice is the main presenting complaint in neonates with cholestasis and usually appears during the first month of life. The majority of the infants appear healthy, and associated clinical features may provide some clues regarding etiology. A history of liver disease in siblings of stillbirths or of consanguinity may portend a genetic or metabolic etiology of the cholestasis. Irritability, poor feeding and vomiting may occur with sepsis or metabolic disorders, including galactosemia and tyrosinemia. The presence of acholic or clay-coloured stools and dark yellow urine are suggestive of obstructive type jaundice as would occur in biliary atresia or severe intrahepatic cholestasis. The abdominal examination may reveal an enlarged, firm liver and splenomegaly. Congenital infections may be associated with low birthweight, microcephaly, purpura and chorioretinitis. Dysmorphic features and heart murmur suggest Alagille syndrome. A complete opthalmological examination should be performed to look for retinal changes or the presence of posterior embryotoxin, which occur in Alagille syndrome. Presence of ascites, edema and coagulopathy indicate severe liver disease.

\section{EVALUATION OF NEONATAL CHOLESTASIS}

In a neonate with prolonged jaundice, a simple test of fractionated serum bilirubin will differentiate cholestatic jaundice from the more common physiological jaundice associated with unconjugated hyperbilirubinemia. This is a necessary first step. A conjugated bilirubin level of more than $20 \%$ of the total bilirubin is abnormal and diagnostic for cholestasis. Unfortunately, prolonged jaundice is often wrongly assumed to be breast milk jaundice or benign physiological jaundice, and the diagnosis of cholestasis is delayed or missed altogether. Therefore, it is highly recom-

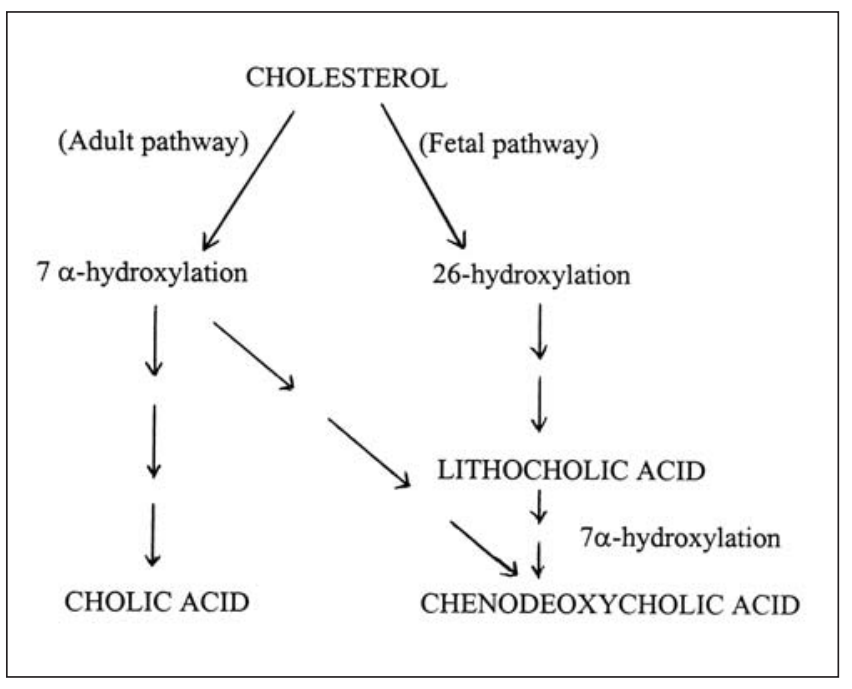

Figure 2) Biosynthesis of primary bile acid, cholic acid and chenodeoxycholic acid from cholesterol showing principal adult and fetal pathways

mended that all neonates who remain jaundiced at four weeks of age should have a fractionated bilirubin screen.

Once the result of the direct hyperbilirubinemia test is obtained and the presence of cholestasis has been established, further evaluation should be conducted promptly to identify treatable disorders, preferably at a centre with expertise in pediatric hepatology. Standard liver biochemical tests usually show variable elevation of conjugated bilirubin, aminotransferase, alkaline phosphatase and gamma-glutamyl transpeptidase $(\gamma-G T)$ concentrations. Low or normal $\gamma$-GT levels in the face of elevation of the aminotransferase and alkaline phosphatase concentrations is a hallmark for the progressive familial intrahepatic cholestasis types I and II (Byler's disease)(10). Infections, especially with Gram-negative organisms, should be excluded by urine and blood cultures. A search for viral agents should be directed based upon the constellations of clinical findings. The list of metabolic disorders causing neonatal cholestasis is exhaustive, but most of these are rare, and specific investigations should depend on the clinical setting (Table 1).

Radiological imaging is useful to help identify surgical causes of neonatal cholestasis. Ultrasonography of the hepatobiliary tree provides valuable information regarding the extrahepatic ducts, liver size and echogenecity. It is virtually the diagnostic test for choledochal cyst. The presence of gallbladder on sonographic assessement does not reliably exclude biliary atresia. Echogeneic renal shadows on ultrasound may be associated with Alagille syndrome. Hepatobiliary scintigraphy using the technetium $99 \mathrm{~m}$ iminodiacetic acid derivatives may be helpful to differentiate biliary atresia from other causes of neonatal cholestasis (11). Five-day pretreatment with phenobarbital enhances biliary flow and increases the sensitivity of this test. Excretion of isotopes into the intestine indicates a patent biliary system and excludes the diagnosis of biliary atresia. Absence of the intestinal phase is suggestive but not specific for biliary 


\section{TABLE 1}

Differential diagnosis of cholestasis in infancy

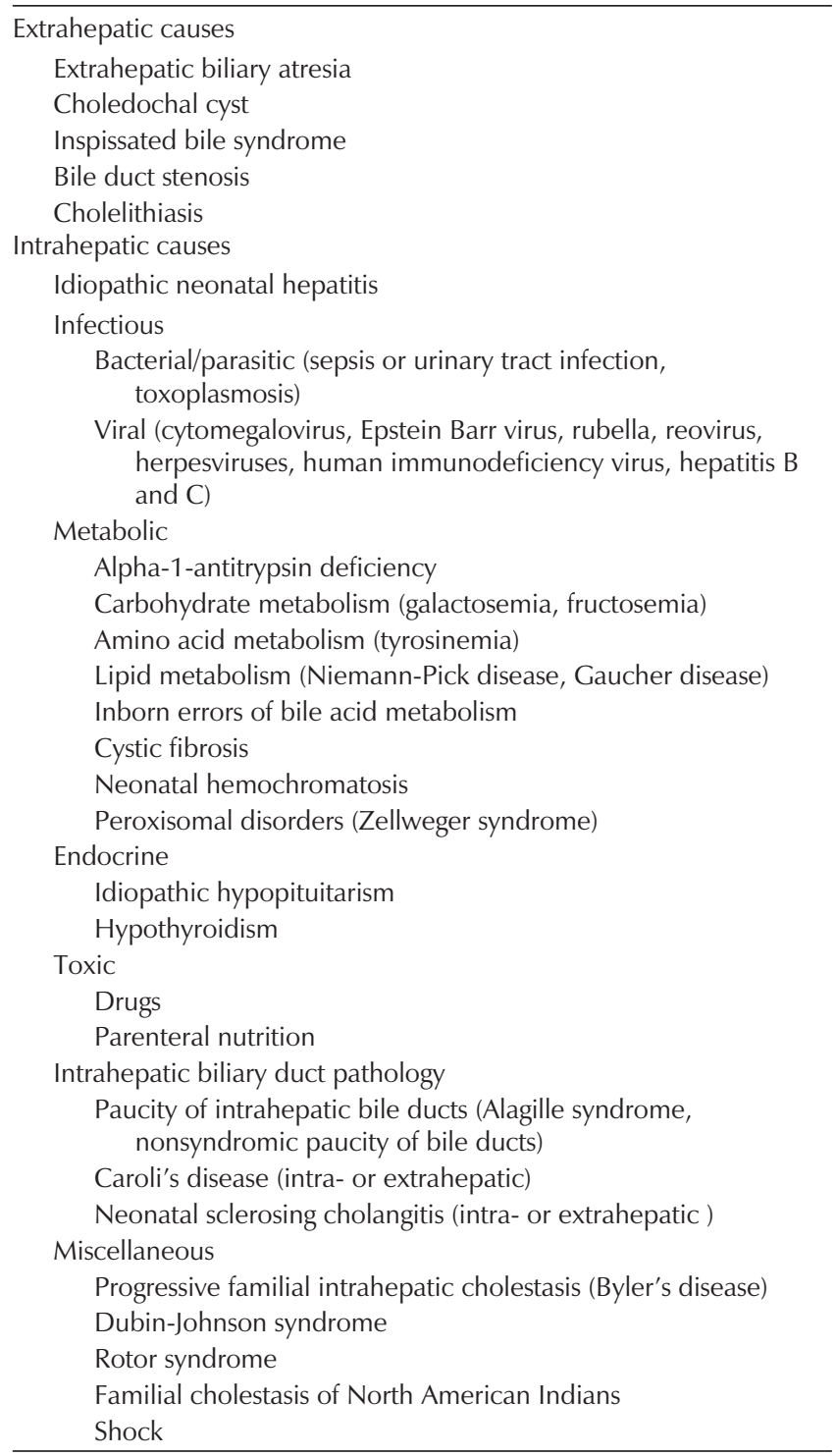

atresia. In doubtful cases, intraoperative cholangiography may confirm patency of the biliary ducts.

Liver biopsy remains the most reliable and definitive procedure in the evaluation of the neonate with cholestasis. The optimal timing for the biopsy is between four and six weeks of age because the histopathological hallmark features for some conditions such as biliary atresia may not be present in the first few weeks of life. Bile duct paucity syndromes are evident by a low ratio (less than 0.9 ) of bile ducts to portal tracts, provided that an adequate number of portal tracts (more than five) are examined (12). In patients with intrahepatic cholestasis, inflammation, lobular changes of focal hepatocellular necrosis, hepatocyte swelling and giant cell transformation are typically observed. Giant cell transformation is a nonspecific response of hepatocytes to injury and is seen in various infective and metabolic disorders.

In contrast, the histopathology of biliary atresia is princi- pally in the portal tract with bile duct proliferation, plugging and inflammation. Electron microscopy of liver tissue is an important adjuvant to the diagnoses of metabolic disorders.

\section{DIFFERENTIAL DIAGNOSIS}

The differential diagnosis of neonatal cholestasis is extensive, but some of the more important causes are listed in Table 1. The three most common causes of neonatal cholestasis are idiopathic neonatal hepatitis, extrahepatic biliary atresia and alpha-1-antitrypsin deficiency, occurring with an approximate frequency of $30 \%$ to $35 \%, 25 \%$ to $30 \%$ and $7 \%$ to $10 \%$ of all cases, respectively (1).

\section{IDIOPATHIC NEONATAL HEPATITIS}

Idiopathic neonatal hepatitis is a clinicopathological syndrome restricted to cases of neonatal hepatitis where liver histology demonstrates giant cell multinucleated hepatocytes and known infectious and metabolic causes of neonatal hepatitis have been excluded. Infants with this condition are often born prematurely and have low birth weight, and their stools are usually pigmented. There may be a history of consanguinity, multiple stillbirths or siblings who were similarly affected with neonatal hepatitis. The diagnosis is one of exclusion, and referral to a pediatric hepatologist is recommended. Because the history and physical findings alone do not allow a reliable distinction between idiopathic neonatal hepatitis and other causes of neonatal cholestasis, further laboratory investigations are dictated by the clinical presentation. The liver biopsy shows classical giant cell transformation of liver cells, lobular disarray, variable inflammation and necrosis. The overall prognosis of idiopathic neonatal hepatitis is difficult to estimate, owing to the variability of clinical course, with about one-third of cases having complete resolution by one year (13). Familial cases of idiopathic neonatal hepatitis appear to have a worse prognosis, while sporadic cases have a more favourable outcome of complete recovery (14). The management is usually supportive, but some patients may go on to require liver transplantation.

\section{EXTRAHEPATIC BILIARY ATRESIA}

Biliary atresia is a major cause of liver failure and the single most frequent indication for liver transplantation in the pediatric age group. The cause of biliary atresia is unclear, but two distinct phenotypes with different causes and pathogenesis have been suggested (15). An embryonic form of biliary atresia, observed in $25 \%$ of cases, is associated with an early onset of cholestasis and the presence of other anomalies including polysplenia, vascular and intestinal malformations. The typical 'perinatally acquired' form is seen in the majority of cases and is without any associated anomalies. The acquired form of biliary atresia may be a result of progressive fibrosclerosing obliteration of extrahepatic bile ducts mediated by immune mechanisms (16). Infants with 'perinatal' biliary atresia are full term at birth and after the first few weeks of life present with jaundice, acholic stools, dark urine and firm hepatomegaly. Hepatobiliary scintigraphy shows the uptake of isotopes by the liver, but excretion 
into the intestine is absent (11). Liver biopsy shows bile plugs, bile ductular proliferation and periportal fibrosis with preserved lobular architecture. An intraoperative cholangiogram may confirm the presence of atretic bile ducts. The treatment of biliary atresia is surgical and involves resecting the sclerosed extrahepatic bile duct and reanastomosing a loop of intestine to the porta hepatis to drain the bile (17). This operation is known as a Kasai procedure, and the age of the child is the single most important factor influencing the surgical outcome. A Kasai procedure before 60 days of life is associated with an $80 \%$ chance of successful biliary drainage, whereas with surgery 90 days after birth the success rate is only 20\% (13). Opportunity for effective surgery is missed with late referral of a child with biliary atresia and the prognosis of untreated biliary atresia is very poor, with an average life expectancy of two years unless liver transplantation is performed. Successful Kasai procedure offers a long term survival (more than 10 years) for about one-quarter of patients without the need for liver transplantation. However, the majority of patients have progressive liver disease following the Kasai procedure, requiring liver transplantation in childhood or adolescence (18).

\section{ALPHA-1-ANTITRYPSIN DEFICIENCY}

Alpha-1-antitrypsin deficiency is the most common metabolic disorder leading to cholestasis in infancy. Alpha-1-antitrypsin, a serum inhibitor of protease activity, is a glycoprotein synthesized and released by the liver into the circulation. In this autosomal, codominantly inherited disorder, a genetic point mutation results in the production of an aberrant alpha-1-antitrypsin glycoprotein that cannot be released from the hepatocyte (19). The clinical picture is indistinguishable from idiopathic neonatal hepatitis. The diagnosis is suggested by low or borderline normal serum alpha-1-antitrypsin levels and should be confirmed by protease inhibitor $(\mathrm{Pi})$ phenotyping. $\mathrm{Pi} \mathrm{ZZ}$ type is associated with liver disease including neonatal cholestasis and pulmonary emphysema later in life. A liver biopsy shows variable degrees of inflammation and necrosis with the distinctive feature of periodic acid-Schiff-positive, diastase-resistant globules in periportal hepatocytes. The prognosis for infants with cholestasis due to alpha-1-antitrypsin deficiency is generally favourable. A long term study of Scandinavian infants with alpha-1-antitrypsin deficiency showed that $80 \%$ to $85 \%$ of patients had minimal, if any evidence of liver dysfunction at 12 years of age (20). The management is supportive with the expectation of improvement in liver function. Liver transplantation may be rarely required for severe progressive liver disease.

\section{MANAGEMENT OF INFANTILE CHOLESTASIS}

Few conditions causing cholestasis in infancy are treatable, and these conditions need timely diagnosis and management. In most cases where there is no cure, the management is supportive. Surgical treatment is required for the extrahepatic causes of cholestasis such as choledochal cyst and biliary atresia. The Kasai procedure has a good success rate if

TABLE 2
Manifestations of deficiency states

performed before two months of age in an infant with biliary atresia. Metabolic causes such as galactosemia, fructosemia and tyrosinemia require specific dietary modification. Endocrine causes can be treated with hormonal replacement. Infectious causes such as urinary tract infection, sepsis and a few of the congenital infections can be readily treated with the appropriate antimicrobial therapy.

Supportive management is directed at optimizing nutrition and growth, and treating the consequences of cholestasis and progressive liver disease. Infants with cholestatic liver disease need a careful and frequent follow-up, preferably at a centre with expertise in pediatric hepatology. Psychosocial support may be necessary for the family to cope with the stress of chronic liver disease in the infant. These patients should receive routine immunizations. As a consequence of cholestasis, lack of bile acids in the intestine leads to fat malabsorption and deficiency of fat-soluble vitamins A, D, E and $\mathrm{K}$. Aggressive nutritional support is necessary for the infant with cholestatic liver disease to achieve their maximum growth potential. These infants should receive approximately $125 \%$ of the recommended dietary allowance based on the ideal body weight. Medium-chain triglycerides provide a rich source of calories for cholestatic infants because their absorption does not require the presence of bile acids in the intestine (21). Nasogastric tube feeds of the concentrated formula may be required to meet optimal caloric intake. Supplementation of vitamins A, D, E and $\mathrm{K}$ is necessary to avoid deficiencies that may occur as early as four months of age. Table 2 shows the manifestation of deficiency states and recommended oral doses of fat-soluble vitamins. Regular monitoring of serum vitamin $A$ and $D$ levels, vitamin E to total serum lipid ratio, and prothrombin time are essential for early detection of vitamin deficiency states. Water-soluble vitamins should be supplemented at twice the recommended daily doses. Minerals and trace elements such as calcium, phosphorus, magnesium, zinc, selenium and iron should be monitored and replaced if necessary. 
Pruritus is a distressing manifestation of cholestasis that may lead to significant clinical morbidity. The pathogenesis of pruritus is poorly understood. Temporary relief from pruritus can be provided with oral antihistaminic agents, but long term management of severe pruritus can be challenging. Phenobarbital ( 5 to $10 \mathrm{mg} / \mathrm{kg} / \mathrm{day}$ ) and cholestyramine (250 to $500 \mathrm{mg} / \mathrm{kg} /$ day) have been used with variable success for the treatment of pruritus. Rifampicin ( $10 \mathrm{mg} / \mathrm{kg} /$ day $)$, which inhibits hepatic uptake of bile acids (22), and ursodeoxycholic acid ( 15 to $30 \mathrm{mg} / \mathrm{kg} /$ day), which alters bile acid composition (23), have been recommended for the treatment of refractory pruritus. Based on the role of the opiate receptor system in pruritus, the opiate antagonist naltrexone was successfully used in recent, select studies (24).

Progressive cholestasis leads to liver cirrhosis and portal hypertension with associated ascites and gastroesophageal varices. Dietary restriction of sodium and diuretics such as spirinolactone ( 3 to $10 \mathrm{mg} / \mathrm{kg} /$ day) are useful in controlling the ascites. Refractory ascites may need frequent therapeutic paracentesis. Gastroesophageal varices are a potentially life-threatening complication of portal hypertension and should be managed accordingly. There are few data concern-

\section{REFERENCES}

1. Dellert SF, Balistreri WF. Neonatal cholestasis. In: Walker WA, Hamilton JR, Durie P, et al, eds. Pediatric Gastrointestinal Disease, 2nd edn. St Louis: Mosby Co, 1996:999-1016.

2. Schreiber RA. Hepatobiliary structure and function. In: Walker WA, Hamilton JR, Durie P, et al, eds. Pediatric Gastrointestinal Disease, 2nd edn. St Louis: Mosby Co, 1996:127-41.

3. Oelkers P, Kirby LC, Heubi JE, Dawson PA. Primary bile acid malabsorption caused by mutations in the ileal sodium-dependent bile acid transporter gene (SLC10A2). J Clin Invest 1997;99:1880-7.

4. Trauner M, Meier PJ, Boyer JL. Molecular pathogenesis of cholestasis. N Engl J Med 1998;339:1217-27.

5. Paulusma CC, Kool M, Bosma PJ, et al. A mutation in the human canalicular multispecific organic anion transporter gene causes the Dubin-Johnson syndrome. Hepatology 1997;25:1539-42.

6. de Vree JM, Jacquemin E, Sturm E, et al. Mutations in the MDR3 gene cause progressive familial intrahepatic cholestasis. Proc Natl Acad Sci USA 1998;95:282-7.

7. Watkins JB. Placental transport: bile acid conjugation and sulfation in the fetus. J Pediatr Gastroenterol Nutr 1983;2:365-73.

8. Ananthanarayanan M, Bucuvalas JC, Schneider BL, Sippel CJ, Suchy FJ. An ontogenically regulated $48-\mathrm{kDa}$ protein is a component of the $\mathrm{Na}(+)$-bile acid cotransporter of rat liver. Am J Physiol 1991;261:G810-7.

9. de Belle RC, Vaupshas V, Vitullo BB, et al. Intestinal absorption of bile salts: immature development in the neonate. J Pediatr 1979;94:472-6.

10. Bull LN, Carlton VE, Stricker NL, et al. Genetic and morphological findings in progressive familial intrahepatic cholestasis (Byler disease [PFIC-1] and Byler syndrome): evidence for heterogeneity. Hepatology 1997;26:155-64.

11. Spivak W, Sarkar S, Winter D, Glassman M, Donlon E, Tucker KJ. Diagnostic utility of hepatobiliary scintigraphy with $99 \mathrm{mTc}$-DISIDA in neonatal cholestasis. J Pediatr 1987;110:855-61.

12. Kahn E, Markowitz J, Aiges H, Daum F. Human ontogeny of the bile duct to portal space ratio. Hepatology 1989;10:21-3.

13. Chang MH, Hsu HC, Lee CY, Wang TR, Kao CL. Neonatal hepatitis: a follow-up study. J Pediatr Gastroentrol Nutr 1987;6:203-7.

14. Deutsch J, Smith AL, Danks DM, Campbell PE. Long term prognosis for babies with neonatal liver disease. Arch Dis Child 1985;60:447-51.

15. Schreiber RA, Kleinman R. Genetics, immunology, and biliary atresia: an opening or diversion? J Pediatr Gastroentrol Nutr $1993 ; 16: 111-3$. ing the use of beta-blockers in pediatric patients with portal hypertension (25). Sclerotherapy or band ligation is indicated to control active hemorrhage. Transjugular intrahepatic portosystemic shunt appears to be a promising therapy for refractory esophageal varices, but the experience with its use in children is limited (26).

Liver transplantation offers an effective treatment for children with end-stage liver disease. Indications for transplantation include irreversiblity, progressive liver dysfunction, severe ascites, recurrent variceal bleeding, refractory pruritus, recurrent cholangitis, encephalopathy, poor synthetic function and poor growth. In a large series of 203 children, the common disorders requiring liver transplantations were biliary atresia $(53 \%)$, fulminant hepatic failure $(8 \%)$, alpha-1-antitrypsin deficiency $(6 \%)$ and familial intrahepatic cholestasis (6\%) (27). Overall, liver transplantation has made a significant impact on the quality of life, growth and survival of children with end-stage liver disease. In a series of 100 children from the United Kingdom, one year survival improved from $71 \%$ in 1983 to $86 \%$ in 1988 (28), and the outcome continues to improve owing to the advances in immunosuppression therapy and surgical techniques.

16. Schreiber RA, Kleinman RE, Barksdale EM, Maganaro TF, Donahoe PK. Rejection of murine congenic bile ducts: A model for immune mediated bile duct disease. Gastroenterology 1992;102:924-30

17. Kasai M. Treatment of biliary atresia with special reference to hepatic porto-enterostomy and its modifications. Prog Pediatr Surg 1974;6:5-52.

18. Karrer FM, Price MR, Bensard DD, et al. Long-term results with the Kasai operation for biliary atresia. Arch Surg 1996;131:493-6.

19. Perlmutter DH. Alpha-1-antitrypsin deficiency: biochemistry and clinical manifestations. Ann Med 1996;28:385-94.

20. Sveger $T$. The natural history of liver disease in alpha-1-antitrypsin deficient children. Acta Paediatr Scand 1988;77:847-51.

21. Kaufmann SS, Murray ND, Wood P, Shaw BW, Vanderhoof JA. Nutritional support for the infant with extrahepatic biliary atresia. J Pediatr 1987;110:679-86.

22. Cynamon HA, Andres JM, Iafrate RP. Rifampicin relieves pruritus in children with cholestatic liver disease. Gastroenterology 1990;98:1013-6.

23. Balistreri WF, A-Kader HH, Heubi JE, Setchell KDR, Whitington P. Ursodeoxycholic acid (UDCA) decreases serum cholesterol levels, ameliorates symptoms, and improves biochemical parameters in pediatric patients with chronic intrahepatic cholestasis. Gastroenterology 1990;98:A566. (Abst)

24. Wolfhagen FH, Sternieri E, Hop WC, Vitale G, Bertolotti M, Van Buuren HR. Oral naltrexone treatment for cholestatic pruritus: a double-blind, placebo-controlled study. Gastroenterology 1997;113:1264-9.

25. Shashidhar H, Langhans N, Grand RJ. Propranolol in the prevention of portal hypertensive hemorrhage in children: a pilot study. J Pediatr Gastroenterol Nutr 1999;29:92-7.

26. Berger KJ, Schreiber RA, Tchervenkov J, Kopleman H, Brassard R, Stein L. Decompression of portal hypertension in a child with cystic fibrosis after transjugular intrahepatic portosystemic shunt placement. J Pediatr Gastrenterol Nutr 1994;19:322-5.

27. Whitington PF, Balistreri WF. Liver transplantation in pediatrics: Indications, contraindications, and pretransplant management. J Pediatr 1991;118:169-77.

28. Salt A, Noble-Jamieson G, Barnes ND, et al. Liver transplantation in 100 children: Cambridge and King's College Hospital series. BMJ 1992;304:416-21. 


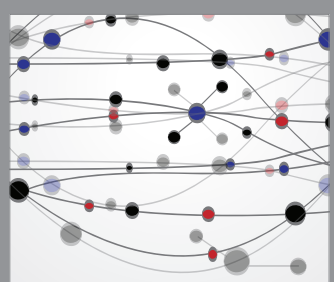

The Scientific World Journal
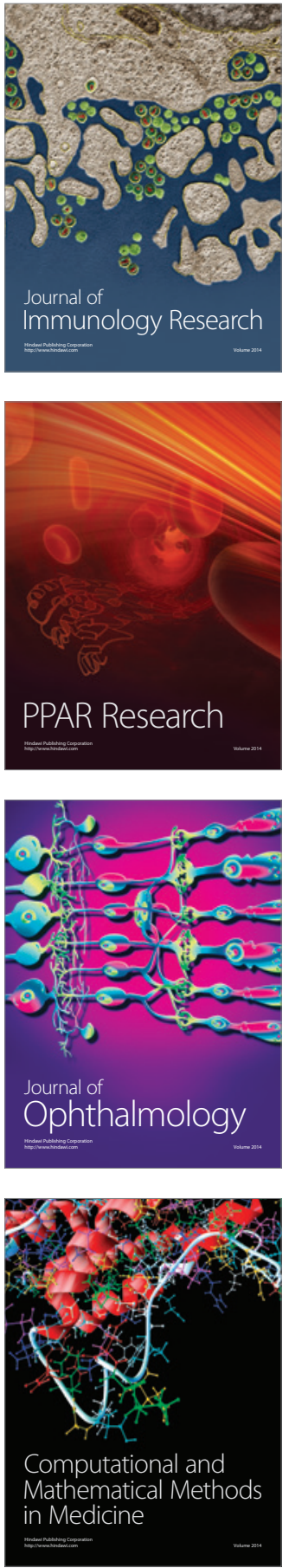

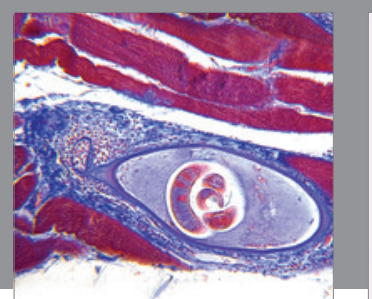

Gastroenterology Research and Practice

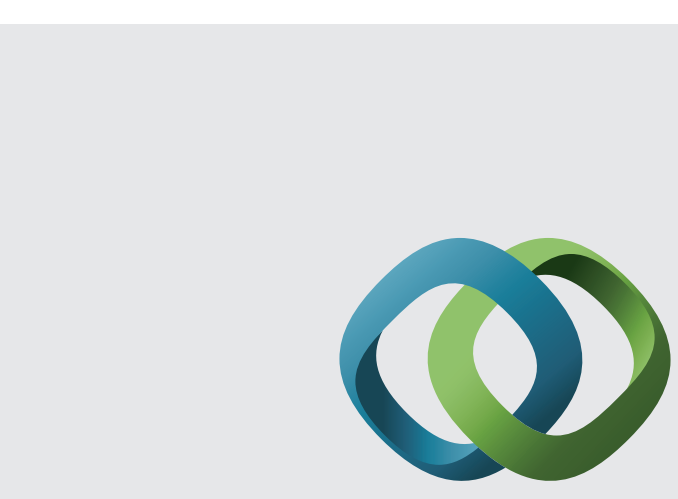

\section{Hindawi}

Submit your manuscripts at

http://www.hindawi.com
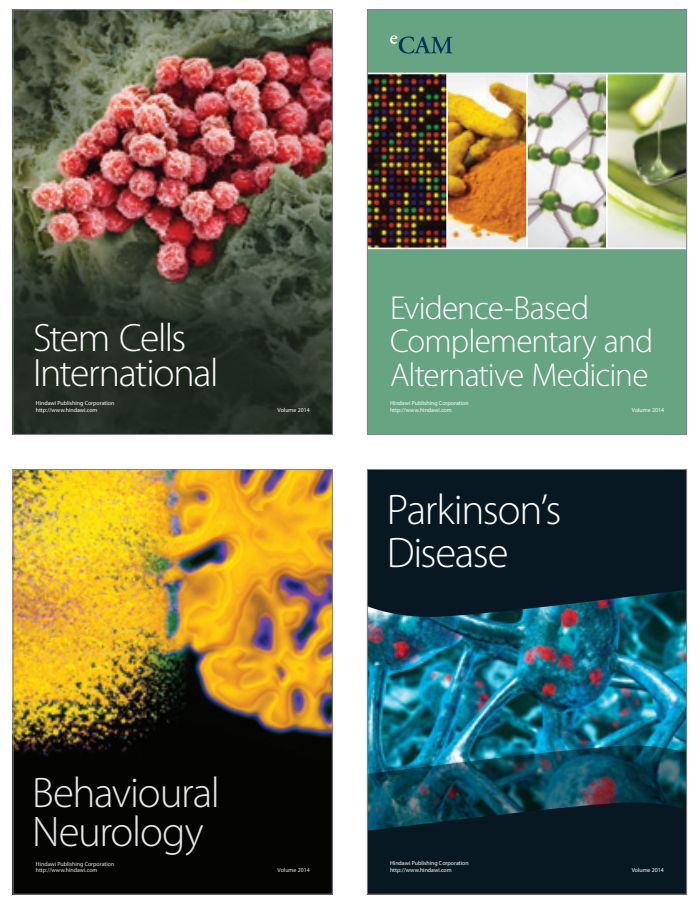
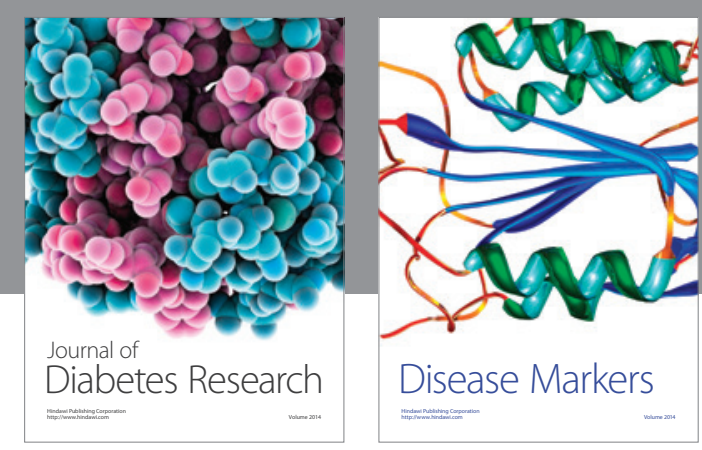

Disease Markers
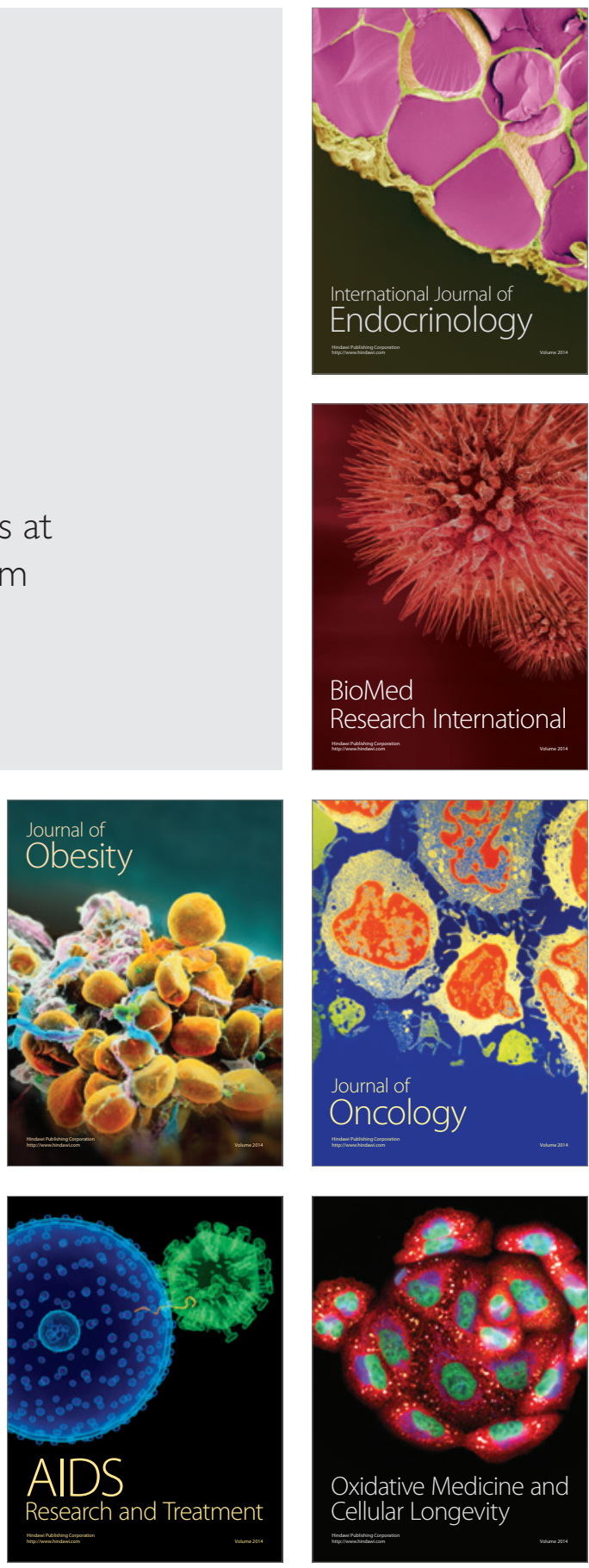